\title{
A comparative study of the growth pattern of the larvae of Culex Linnaeus, I 758 in various water bodies and the implications for environmental control
}

\begin{abstract}
In an attempt to understand the best water body that could best support the growth of Culex Linnaeus, 1758 mosquitoes to further elucidate the best method that could be applied in their control in an assumed evolution of habitat, a total of 50 larvae were collected from a pond. Test was then conducted in five different sources of water and the mortality of the larvae in the different sources of water and lengths were observed. Mortality of larvae was highest in the urine and water mixed with detergent where all 10 larvae in both containers died. Their high rate of mortality could be attributed to the presence of organic salts and urea present in the urine killed the larvae and also the presence of chemicals (Sodium Sulphate, Sodium Carbonate, and Sodium Silicate) present in the detergent led to the death of the larvae. Oxygen which is needed by the larvae for respiration was in short supply due to the presence of the oil leading to the death of the larvae. However, the dirty and clean water recorded the least mortality of larvae as only 1 larva died in each of the containers with dirty and clean water. The larvae died probably because of lack of sufficient food. Based on the mean lengths of the larvae in each of the sources of water, the larvae in the dirty water had the longest lengths. Dirty water encouraged the growth of larvae because it has nutrients and many micro organisms such as bacteria and algae that the larvae feed on for growth and further development. Although the larvae in the clean water also had longer lengths but they were not as long as those in the dirty water. On the other hand, the larvae in the water mixed with detergent and the oily water had shorter lengths while those in the urine had the shortest lengths. There was no significant difference in the lengths of larvae measured from the different water bodies. Based on the findings from our result, it could therefore be concluded that dirty water best support the growth of Culex despite the recorded growth in the clean water. We therefore infer that inspite the attempt by Culex in undergoing evolution of habitat, the best environment that supports their growth is still the dirty water.
\end{abstract}

Volume 3 Issue 3 - 2018

\author{
Goselle ON, Gyang DA, Adara OF, Effiong \\ KT, Nanvyat N, Barshepn Y, Matur BM, \\ Kumbak D, Ahmadu YM, Mafuyai HB \\ Department of Zoology,Applied Entomology and Parasitology \\ unit, University of Jos, Nigeria
}

Correspondence: Goselle Obed Nanjul, Department of Zoology, Applied Entomology and Parasitology unit, University of Jos, Nigeria. P.M.B. 2084 Jos, Email obeto247@yahoo.com

Received: May 17, 2018| Published: June II, 2018

\section{Introduction}

Mosquitoes are true flies belonging to the order Diptera Linnaeus, 1758 and like all true flies they have two wings but differ in that their wings have scales. There are over 3,000 different species of mosquitoes throughout the world and are the most important of pathogenic organisms. ${ }^{1}$ They are the most important insects affecting human health ${ }^{2,3}$ and they alone transmit diseases such as malaria, filariasis, dengue yellow fever and Japanese encephalitis to more than 700 million people annually, ${ }^{4-6}$ majorly in tropical and sub-tropical regions of the world. ${ }^{7}$ Culex mosquito whose adult ranges between 4 and $10 \mathrm{~mm}$ in length is a genus that has a number of species that acts as a vector for several diseases such as Japanese encephalitis, West Nile virus, St. Louis encephalitis, filariasis and avian malaria. ${ }^{8}$ Just like other insects, the Culex mosquito also has three body parts namely head, thorax and abdomen but unlike the other mosquitoes, the Culex mosquito has a very interesting wing structure. Instead of two pair of wings, it has only a single pair similar to flies. Despite the large number of the species of mosquitoes, they differ in the type of aquatic habitats they prefer for oviposition based on the location, the physico-chemical condition of the water body, and the presence of potential predators. ${ }^{9,10}$ Physico-chemical factors that influence oviposition, survival, and the spatio-temporal distribution of important diseases vector species include salts, dissolved organic and inorganic matter, degree of eutrophication, turbidity, presence of suspended mud, presence or absence of plants, temperature, light and shade, and hydrogen ion concentration. ${ }^{11-13}$ Understanding how these factors affect the distribution of a particular vector species and how they influence larval abundance is an essential component of larval biology and of great importance in the design and implementation of integrated vector management plans. It has been argued and published in different journals and have been accepted as a norm that Culex mosquitoes are majorly able to breed only in dirty water, polluted waters such as sewage, and sullage water collections in septic tanks and have phobia for clean water. But few studies have shown that they can also breed in comparatively clean water if collections of 
such types of polluted water are absent. For instance in few studies that examined the relationship between habitat characteristics and larval abundance in the Orange County, the distribution of Culex tarsalis Coquillett, 1896 was reported to be significantly associated with the percent cover by Typha L. species root masses and Typha species stem density per square meter. ${ }^{14}$ But in Malaysia, the larvae of Culex quinquefasciatus Say, 1823 were most abundant in polluted drains containing 1.0 to $2.0 \mathrm{gl}$ liter of dissolved oxygen, 1.0 to $2.4 \mathrm{gl}$ liter of soluble reactive phosphate and $0.1-0.9$ gl liter of ammonia Cal nitrogen. ${ }^{15}$ Consequently, the need to have an alternative control measure against the larvae aside the application of insecticide is of utmost importance. It is in this view that the aim of the work is to evaluate and compare the growth pattern of the larvae of Culex in various water bodies and the implication for environmental control. Other objectives were to establish if other sources of water aside dirty water are employed for breeding by Culex, to establish if the growth of features in larvae are of the same length in different bodies of water, to establish if alternative environmental control measures could be employed towards control of larval stages and mitigation of diseases transmitted by Culex mosquitoes and to infer where possible that Culex mosquitoes are evolving with changes to environment

\section{Materials and methods}

\section{Study area, study location and sample collection}

The study area is the University of Jos, main campus, located in the Northern region of Jos, the Plateau State capital, Nigeria. It lies on latitude $9^{\circ} 56^{\prime} 58.7^{\prime \prime}\left(9.9496^{\circ}\right) \mathrm{N}$, longitude $8^{\circ} 53^{\prime} 22.3^{\prime \prime}$ $\left(8.8895^{\circ}\right) \mathrm{E}$ and an elevation of 1,173 meters (3,848 feet).The study was conducted in the Undergraduate laboratory of the Department of Zoology, University of Jos. Larvae of Culex species were collected from a pond behind the Undergraduate laboratory of the Department of Zoology, University of Jos, Bauchi road.

\section{Methods of collection}

Larvae of Culex species were collected in the morning from the pond into labelled plastic containers containing water from the pond. These larvae were transported to the laboratory and separated based on instars. The late 2 nd instars and early $3^{\text {rd }}$ instars were used for the experiments.

\section{Collection technique}

A total of 50 Culex larvae were collected from the pond, 10 larvae were each placed in five different labelled plastic containers containing different sources of water.

The sources of water included:

Clean water: Collected from a well within University of Jos, main campus;

Dirty water: This was obtained from a pond behind the undergraduate laboratory of the Department of Zoology, University of Jos.

Water mixed with detergent: (omo- made up mainly of Sodium Sulphate, Sodium carbonate and Sodium silicate), which was mixed with water to get a solution.

Oily water: Where clean water was mixed with pure vegetable oil to get the oily water. When mixed together, the oil and the water still separated with the oil floating to the top because it is less dense than the water. Oil and water don't mix because water molecules are more attracted to each other than to oil molecules

Urine sample: This consisted mainly of urea, organic salts, water and other biological wastes products. Five different labelled plastic containers were filled with $30 \mathrm{ml}$ of each of these liquids i.e the clean water, dirty water, water mixed with detergent, oily water and urine. In each of these plastic containers, 10 Culex larvae were placed and transferred into two wooden boxes covered with fine mesh net to allow proper aeration and observed for a period of two days in the laboratory.

\section{Laboratory identification of mosquito larvae}

The larvae collected were taken to the laboratory for further identification to differentiate Culex species from non Culex species. Characters used to differentiate Culex species from non Culex species were the presence of short, stout breathing tube with one pair of hair tuft present in Culex species. A single larva was placed on a slide and identified with the use of a light microscope to confirm if the larvae collected from the river were Culex species.

\section{Determination of the length of culex larvae}

The lengths of the larvae were measured using the eyepiece micrometer (Micrometer $(\mu \mathrm{m})$ is one thousandth of a millimeter). The eyepiece micrometer is used in place of the standard eyepiece of the microscope. It has a series of numbered lines inside of it which makes it look like a ruler. Each larva was placed on a clean slide and the length was measured separately. The whole length of a single larva was measured from the siphon to the head of the larva. The point at which the head of the larva ends is considered the length in millimeter. This length in millimeter is multiplied by the objective lens of the microscope. For this experiment, an objective lens of $\mathrm{x} 1$ was used. After multiplying the length by the objective lens of the microscope, the number obtained is converted to micrometer by multiplying the length by 1000 .

For example: If the whole length of larva from the eyepiece micrometer is $0.55 \mathrm{~mm}$, objective lens of microscope used is $\mathrm{x} 1$. Then the whole length of larva in millimeter is $0.55 \times 0.001=0.00055$ $\mathrm{mm}$. To convert this length to micrometer: $0.00055 \times 1000=0.55$ micrometer.

\section{Statistical analysis}

The data obtained in this study was subjected to one-way ANOVA analysis using statistical package for Social Sciences (SPSS) data analysis platform.

\section{Results and analysis}

\section{Results}

A total of 50 larvae were collected from the pond. The test was conducted in five different sources of water. Table 1 shows the mortality of the larvae in the different sources of water. Mortality of larvae was highest in the urine and water mixed with detergent as all 10 larvae in both containers died. Their high rate of mortality could be attributed to the presence of organic salts and urea present in the urine killed the larvae and also the presence of chemicals (Sodium Sulphate, Sodium Carbonate, and Sodium Silicate) present in the detergent led to the death of the larvae. In the oily water, 8 larvae died after a period of two days. The oil floating on top the water prevented oxygen from getting into the water. Oxygen which is needed by the larvae for respiration was in short supply due to the presence of the oil. Inadequate oxygen led to the death of the larvae. However, the dirty and clean water recorded the least mortality of larvae. Only 1 larva died in each of the containers with dirty and clean water. The larvae died probably because of lack of sufficient food. 
Figure 1 shows the mean lengths of the larvae in each of the sources of water. The larvae in the dirty water had the longest lengths. This shows that the growth rate was highest here. Dirty water encouraged the growth of larvae because it has nutrients and many micro organisms such as bacteria and algae that the larvae feed on for growth and further development. Although the larvae in the clean water also had longer lengths but they were not as long as those in the dirty water. In essence, clean water also encourages the growth of the larvae. On the other hand, the larvae in the water mixed with detergent and the oily water had short lengths while those in the urine had the shortest lengths. There was no significant difference in the lengths of larvae measured from the different water bodies. A graphical
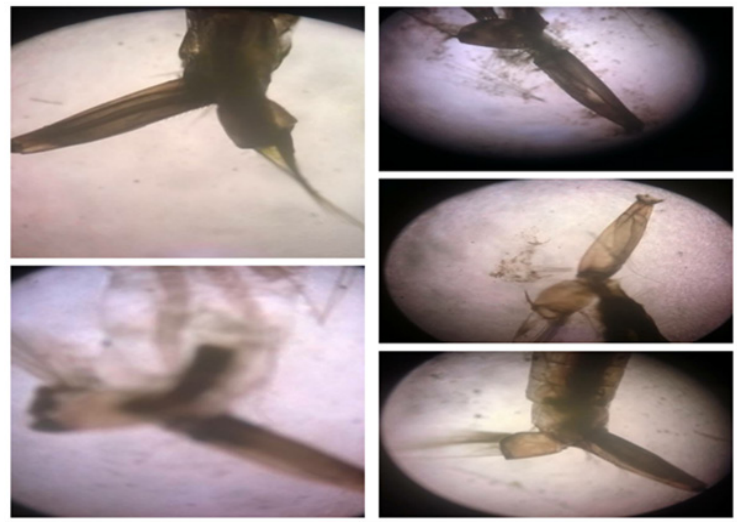

Figure I Siphons of larvae from A) Detergent B) Urine C) Oily water

D) Clean water E)Dirty water. representation of the lengths in the various water bodies is as shown in Figure 1. The graph below shows the mean lengths of the larvae and how each source of water affected the growth of the larvae which in turn affected the lengths of the larvae. From the graph, there was a decline in growths of larvae that were placed in urine and water mixed with detergent. There was a gradual increase in lengths of larvae from oily water. The larvae from the clean and dirty water both increased in length but the larvae from dirty water recorded the highest increase in lengths. The different water sources had impacts on the siphons of the larvae. The shape of the siphons of the larvae from the different water sources is shown in the Figure 2.

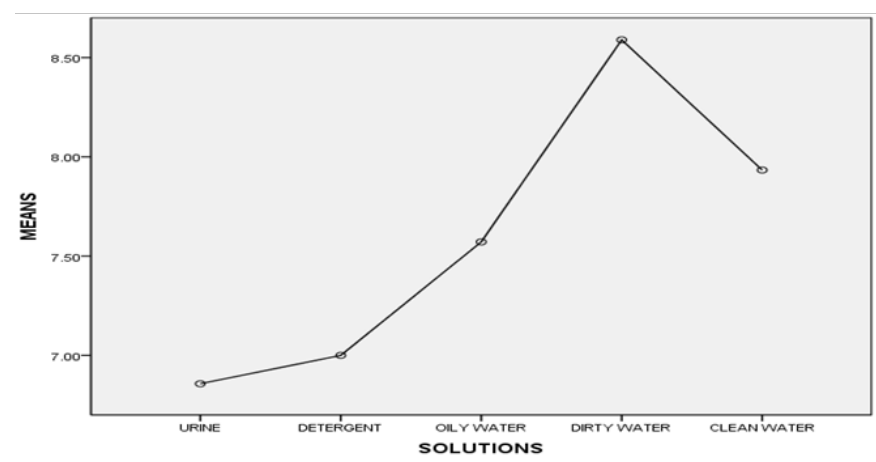

Figure 2 Graph showing the mean lengths of larvae from 5 different water sources

Table I Mortality number of Culex species larvae in various water bodies

\begin{tabular}{llll}
\hline S/No & Source of water & Initial number of larvae & Number of dead larvae (\%) \\
\hline 1 & Dirty water & 10 & $\mathrm{I}(10)$ \\
2 & Clean water & 10 & $\mathrm{I}(10)$ \\
3 & Oily water & 10 & $8(80)$ \\
4 & Water mixed with Detergent & 10 & $10(100)$ \\
5 & Urine & 10 & $10(100)$ \\
\hline
\end{tabular}

\section{Discussion}

The results of this research work showed the different effects of the five different sources of water on the growth, length and siphon of the larvae of Culex mosquitoes. The abundance of Culicine and Anopheline mosquito species may be as a result of their ability to survive in diverse environments as previously reported by Dondorp et al. ${ }^{16}$ The high mortality of the larvae observed in the urine, oily water and water mixed with detergent could mean that these water sources are deadly and not suitable for the growth and development of the larvae. The low mortality of the larvae in the dirty and clean water may be as a result of their ability to survive and thrive well in these sources of water. The larvae were longer compared to other larvae from urine, oily water and water mixed with detergent. The survival of larvae in dirty and clean water suggests that the environmental conditions in these ecosystems were complex and favorable to survival of these vectors as also observed by Adeleke et al. ${ }^{17}$ This suggests that the conditions in the dirty water and clean water were favorable to support the continual growth and survival of the larvae. This agrees with the findings of Spielman et al. ${ }^{18}$ Andreadis et al. ${ }^{19}$ on Culex pipiens Linneaus, 1758 mosquitoes in their study in urban environments where they found them to be abundant and that they use storm drains and other sources of organically rich, stagnant water for oviposition and larval development. The shape of the siphon of the larvae from oily water, water mixed with detergent and urine changed while that of the larvae from clean and dirty water remained unchanged. The difference in the physiology of the siphon of these larvae could have been influenced by the chemicals present in the urine and the detergent. ${ }^{20-29}$

\section{Conclusion}

The current report highlights that Culex larvae can grow effectively in dirty and clean water. These water sources have no effect on their growth, development, siphon and survival. However, these larvae cannot thrive and survive in oily water, water mixed with detergent and urine because these sources of water negatively influenced body size, siphon and survival. The reason for the reduced body lengths, damaged siphon and high mortality rate may be either due to the nutritional status of the water or due to the chemical substances present 
in the urine and detergent which are detrimental to development of the larvae.

\section{Recommendations}

The findings of this study should serve as baseline information to checkmate the population of mosquito larvae and to bolster efforts to control various diseases that are transmitted by Culex mosquitoes by exploring water quality conditions of Culex larval habitats that produce adult mosquitoes.

\section{Contributions}

ONG conceived and designed the study and wrote the manuscript. GDA, AOF, EKT, NN, YB, KD, AYM, BMM, MHB conducted the research work by collecting and identifying of larvae and also contributed to the writing of the manuscript. ONG and YB carried out data analysis.

\section{Acknowledgements}

We are grateful to the Department of Zoology, University of Jos for the kind support and during the research work. The study was conceived and finalized at the Applied Entomology and Parasitology Unit of the Department of Zoology, University of Jos, Nigeria.

\section{Competing interest}

There were no financial or non-financial competing interests influencing the interpretation of data or presentation of information to our work.

\section{References}

1. Vinogradova EB. Culex pipens pipens, mosquitoes: taxonomy distribution, ecology, Physiology, genetics, applied importance and contol. Pensoft, Sorfia, Bulgaria, Europe; 2000.

2. Awolola T, Idowu E, Adeneye A, et al. Entomological survey and infection rates of Plasmodium falciparum and Wuchereria bancrofti in mosquito populations in the Kainji Lake Area, Nigeria. Nigerian Journal Parasitology. 2006;27:58-61.

3. Ghosh A, Chowdhury N, Chandra G. Plant extracts as potential larvicides. Indian J Med Res. 2012;135(5):581-598.

4. Taubes, Anyanwu JU, Agbede RI, Ajenusi OJ, et al. A survey of Culicine mosquitoes in a Northern Guinea Savannah Town of Zaria, Kaduna State. Nigerian Journal of Parasitology. 1999;20:137-148.

5. Center for Disease Control. Vector Control. Nigeria; 2008.

6. Center for Disease Control and Prevention. Assessing Capacity for Surveillance, Prevention, and Control of West Nile Virus InfectionUnited States; 1999 and 2004. 2006;55(6):150-153.

7. Dua VK, Pandey AC, Dash APP. Adulticidal activity of essential oil of Lantana camara leaves against mosquitoes. Indian $J$ Med Res. 2010;131:434-439.

8. Hamer GL, Anderson TK, Donovan DJ, et al. Dispersal of Adult Culex Mosquitoes in an Urban West Nile Virus Hotspot: A Mark-Capture Study Incorporating Stable Isotope Enrichment of Natural Larval Habitats. PLoS Negl Trop Dis. 2014;8(3):e2768.

9. Muturi EJ, Mwangangi J, Shililu J, et al. Mosquito species succession and physic-chemical factors affecting their abundance in rice fields in Mwea, Kenya. J Med Entomol. 2007a;44(2):336-344.

10. Piyaratnea MK, Amerasinghe FP, Amerasinghe $\mathrm{PH}$, et al Physicochemical characteristics of Anopheles culifacies \& Anopheles varuna breeding water in a dry zone stream in Sri Lanka. J Vector Borne Dis. 2005;42(2):61-67.
11. Cheng SS, Huang CG, Chen YYJ, et al. Chemical compositions and larvicidal activities of leaf essential oils from two eucalyptus species. Bioresour Technol. 2009:100(1):452-456.

12. Darsie RF, Ward RA, Chang CC, et al. Identification and Geographical distribution of the mosquitoes of North America, north of Mexico. University Press of Florida, USA; 2004. 67 p.

13. Heningway J, Ranson H. Insecticide Resistance in Insect Vectors of Human Disease. Annu Rev Entomol. 2000;45:371-391.

14. Moller Jacobs LL, Murdock CC, Thomas MB. Capacity of mosquitoes to transmit malaria depends on larval environment. Parasites \& Vectors. 2014;7:593.

15. Gimnig J, Ombok M, Kamau L, et al. Characteristics of larval anopheline (Diptera: Culicidae) habitats in Western Kenya. J Med Entomol. 2001;38(2):282-288.

16. Muturi E, Shililu J, Gu W, et al. Larval habitat dynamics and diversity of Culex mosquitoes in rice agro-ecosystem in Mwea, Kenya. Ame J Trop Med. 2007b;76(1):95-102.

17. Hassan A, Narayanan V, Salmah M. Observations on the physicochemical factors of the breeding habitats of Culex quinquefasciatus. Journal of Vector Ecology. 1993;125(5):34-376.

18. Dondorp A, Francois N, Poravuh Y, et al. Artemisinin resistance in Plasmodium falciparum Malaria. New England Journal of Medicine. 2009;361(5):455-467.

19. Adeleke MA, Mafiana CF, Idowu OA, et al. Population Dynmics of indoor, sample mosquitoes and their implication in disease transmission in Abeokuta, South-Western Nigeria. J Vector Borne Dis. 2010;47(1):3338.

20. Spielman A, D’Antonio M. Mosquito: a natural history of our most persistent and deadly foe. Hyperion; New York; 2001.

21. Andreadis TG, Anderson JF, Vossbrinck CR, et al. Epidemiology of West Nile virus in Connecticut: A five-year analysis of mosquito data 19992003. Vector-Borne and Zoonotic Diseases. 2004;4:360-378.

22. National Vector Borne Diseases Control Programme (NVBDCP) Directorate General of Health Services, Ministry of Health and Family Welfare, Nigeria; 2012.

23. Nelson MJ. Mosquito studies (Diptera, Culicidae). XXCI. Winter biology of Culex tarsalis in imperial valley, California. American Entomological Institution. 1971;7:1-56.

24. Ramaiah KD, Das PK, Michael E, et al. The Economic Burden of Lymphatic filariais in India. Parasitology Today. 2000;16(6):251-253.

25. Reisen WK, Brault AC. West Nile virus ib North America: Perspectives on epidemiology and intervention. Pest Manag Sci. 2007;63(7):641-646.

26. Reisen WK, Reeves WC. Epidemiology and control of mosquito-Borne Arboviruses in California, 1943-1987. California Mosquito and vector control Association; Sacramento, CA 1990. Bionomics and ecology of Culex tarsals and other potential mosquito vector species. USA. 1990;508.

27. Reynolds Michael MC, Hellenthal DR. Environment influences on mosquito Adult and Larvae Abundance. University of Notre Dame Environmental Research Centre, USA; 2003.

28. Tiwary M, Naik SN, Tewary DK, et al. Chemical Composition and Larvicidal activities of the essential oil of Zanthoxylum armatum. DC (Rutaceae) against three mosquito vectors. J Vector Borne Dis. 2007;44(3):198-204.

29. World Health Organization. Chemical methods for the control of vectors and pests of Public Health Importance. WHO, Geneva; 2004. 109 p. 